Hospital from January 2009 to December 2011. Ultrasounds with Grade III or IV IVH or PVL were excluded. The data collected was grouped according to gestational age at the time of scan from 24 weeks to 32 weeks.

Results 634 cranial ultrasounds from 255 infants were reviewed. The median values show a general trend of increase as gestation increases.

Abstract 1269 Table 1 Levene Index versus Gestation

\begin{tabular}{lll}
\hline Gestation (643 scans) Weeks & Left Median(range)mm & Right Median(range)mm \\
\hline $24(n=21)$ & $7.91(7.62-8.21)$ & $8.02(7.93-8.12)$ \\
$25(n=42)$ & $8.11(4.4-11.29)$ & $8.17(5.66-9.87)$ \\
$26(n=71)$ & $8.26(5.52-11.01)$ & $8.02(5.05-10.26)$ \\
$27(n=74)$ & $8.18(5.41-11.43)$ & $7.73(3.95-12.29)$ \\
$28(n=99)$ & $8.32(5.02-29.39)$ & $8.24(4.49-29.39)$ \\
$29(n=100)$ & $8.89(5.77-12.67)$ & $8.39(5.22-11.73)$ \\
$30(n=89)$ & $9.35(6.51-13.17)$ & $8.61(4.75-12.46)$ \\
$31(n=91)$ & $8.82(6.09-13.42)$ & $8.2(4.86-13.81)$ \\
$32(n=47)$ & $9.61(6.02-11.8)$ & $8.62(4.86-13.81)$ \\
\hline
\end{tabular}

Conclusion This study shows that there is a slight increase in Levene index as gestation at the time of scan increases.

\section{PREDICTIVE VALUE OF AMPLITUDE INTEGRATED EEG (AEEG) IN NEONATAL SEIZURES AND NEURODEVELOPMENTAL OUTCOME}

doi:10.1136/archdischild-2012-302724.1270

S Beken, K Gücüyener, Ş Soysal, I Hirfanoglu, Ö Turan, E Ergenekon, F Kulalı, N Altuntaş, S Ünal, E Kazancı, E Önal, C Türkyılmaz, E Koç, Y Atalay. Gazi University Hospital, Ankara, Turkey

Background and Aim Seizures in the neonatal period represent a neurological emergency but it is often challenging for the clinican to recognize it with only visual inspection. Our aim is to evaluate the use of amplitude integrated EEG (aEEG) as a prognostic tool in neonatal intensive care unit (NICU) patients with clinical seizures in the two years follow-up.

Method Twenty-four infants with clinical seizures (Group I) and 67 infants with suspected seizure activity (Group II) were included in the study. All infants were monitored with aEEG at least 24 hours after the seizure activity were stopped. aEEG was analysed for background activity, sleep-wake cycle and seizure activity. All infants were followed up in our outpatient clinic had neurologic examination and Bayley II Infant Development Scale were done by the same neuropsychologist on the 6th, 12th, 15th and 18th months of age.

Results Median gestational age of the infants were 36.0 weeks $\left(26^{1 / 7}-41^{3 / 7}\right)$. There was no significant difference between groups regarding to Bayley scores. Mechanical ventilation, sepsis, inotrope use were more in Group I in which there were more critically ill infant. These critically ill infants tend to have lower Bayley scores in Group I. In Group I infants with normal background activity tend to have higher Bayley scores than those of whom had discontinuous, low valtage, burst supression activity.

Conclusion aEEG helps management of infants with seizure activity allowing continuous long-term monitoring of brain functions. Continous background activity seems to be a good predictor of aEEG in infants with neonatal seizure.

\section{RISK FACTORS FOR INTRAVENTRICULAR HEMORRHAGE IN LESS THAN 32 WEEKS GESTATION PRETERM INFANTS - PROSPECTIVE STUDY}

${ }^{1} \mathrm{ML}$ Ognean, ${ }^{2} \mathrm{E}$ Olariu, ${ }^{2} \mathrm{O}$ Boanta, ${ }^{2} \mathrm{~A}$ Nicula, ${ }^{2} \mathrm{~V}$ Panait, ${ }^{3} \mathrm{G}$ Man. ${ }^{1} \mathrm{Clinical}$ County Hospital Sibiu; ${ }^{2}$ Neonatology, Clinical County Hospital Sibiu; ${ }^{3}$ Neonatology, Clinical Center Mostar, Sibiu, Romania

Intraventricular haemorrhage (IVH) is one of the most important of morbidity and mortality causes in preterm infants.

Aim To evaluate the incidence and risk factors for IVH in $\leq 32$ weeks gestation preterm infants.

Methods The study was developed in the Neonatology Dpt. of the Clinical County Emergency Hospital Sibiu between 01.01. 2010-31.12.2011. The study group comprised 139 preterm infants with a mean GA of $30.26 \pm 1.93$ weeks (24-32 weeks) and a mean BW of $1412.99 \pm 367.389 \mathrm{~g}(600-2270 \mathrm{~g})$. The prospectively collected data were analysed using IBM SPSS 19.0 and were considered significant at a $\mathrm{p}<0.05$.

Results The incidence of IVH in the study group was $50.35 \%$ whilst grade 3 and 4 were encountered with an incidence of $5.03 \%$. The preterm infants with IVH had significantly lower BW ( $p$ 0.000), GA ( $p$ 0.000), and Apgar score at 1 minute ( $p$ 0.023). The duration of oxygen therapy, the need for surfactant administration, oxygen duration on CPAP, mechanical ventilation length and the length of hospitalization were significantly greater for the infants with IVH compared with those with normal ultrasound scans. Apnoea of prematurity, PDA and ROP were significantly associated with the presence of IVH $(0.001-$ 0.030). Being outborn was also an important risk factor for IVH.

Conclusion The analysed data showed similar results - for the incidence and risk factors for IVH - as previously published data in the literature, revealing that between the analysed factors - the severity of the respiratory distress syndrome is one of the major risk factors for IVH in preterm infants.

\section{SURVIVAL AND NEURODEVELOPMENTAL OUTCOME OF PRETERM INFANTS WITH A GESTATIONAL AGE OF 22 TO 26 WEEKS IN A REGIONAL CENTRE}

doi:10.1136/archdischild-2012-302724.1272

P Kutz, S Supcun-Ritzler, C Roll. Department of Neonatology and Pediatric Intensive Care, Vest Children's Hospital, University of Witten-Herdecke, Datteln, Germany

Background and Aims Counselling parents of extremely preterm infants requires knowledge on results of large population-based cohorts and contemporaneous local data.

Methods We assessed the outcome of all live-born infants 2006 to 2009 with a gestational of 22 to 26 weeks (outborns admitted to neonatal care and all inborns). At a corrected age of 24 months infants underwent Bayley Scales of Infant and Development II testing, clinical and neurological examinations.

Results There were 105 infants $<27$ weeks born alive, with a median birth weight of $675 \mathrm{~g}$ (range 300-1300 g), of whom $23(22 \%)$ died before discharge; ( $\leq 22$ weeks 9/10; 23 weeks 9/18; 24 weeks: 3/22; 25 weeks 1/22; 26 weeks: 1/33). Two infants died after discharge. Complete follow-up data are available in 74 (93\%) of the 80 survivors. The median MDI score was $94 ;>84$ in $44(59 \%), 84-70$ in $20(27 \%)$, and $<70$ in $10(14 \%)$ infants. The median PDI score was 98 ; >84 in 53 (72\%), 84-70 in 12 (16\%), and < 70 in $9(12 \%)$ infants. None of the children were blind or deaf, 14 had glasses, 5 required hearing aids. Overall, neurodevelopment was classified as normal in 45 of 74 (61\%) infants (22 weeks: 0/1; 23 weeks: 1/7; 24 weeks: 10/17; 25 weeks: 12/19; 26 weeks: 22/30).

Conclusions The rates of overall survival (76\%) and normal neurological development among survivors $(61 \%)$ were similar to contemporaneous data from for Sweden (70\%) and the Stockholm area (65\%), respectively. OUTCOME - MOROCCAN DATA 